\title{
FGDP UK separates from the Royal College of Surgeons of England
}

On 31 July 2021, the Faculty of General Dental Practice UK (FGDP UK) completed its separation from the Royal College of Surgeons of England (RCS England) to join the new College of General Dentistry, realising the ultimate ambition of its founding members to establish an independent college for general dental practice.

At the start of its $25^{\text {th }}$ anniversary year in 2017, the Faculty announced that it would begin preparing for independence. The July separation sees FDGP UK's charitable functions transferred to the College of General Dentistry (CGDent), which was formally launched earlier in July.

RCS England has long supported dental surgeons and is proud of its role in providing an academic home for general dental professionals for over 40 years. The Faculty of Dental Surgery (FDS), which remains at RCS England, first held an examination for general dental practitioners, the Membership in General Surgery, in 1979.

Since its establishment in 1992, FGDP UK's mission has been to positively influence oral health through the education of the general dental professions and the provision of evidence-based guidance. The CGDent will now assume these responsibilities and is grateful to RCS England for its role in establishing the FGDP, and for enabling it to grow and thrive in preparation for its eventual independence.

FGDP UK and FDS have frequently collaborated, perhaps most notably in the delivery of the MJDF (Membership of the Joint Dental Faculties) examination, and RCS England and CGDent are committed to continuing to work together going forward in the interests of the dental professions and the patients they serve.

\section{New study brings hope of further decline in dental decay in UK children}

The role of water fluoridation in strengthening children's primary teeth has been given further affirmation by a new Canadian study. ${ }^{1}$ A 14-year comparison of schoolchildren aged around seven found that children in fluoridated Edmonton had fewer cavities and thus healthier teeth than in non-fluoridated Calgary.

Due to its scale and precision, the research is important on many levels, not least because it showcases what happens when water fluoridation is stopped. In 2011, the municipal government in Calgary decided to discontinue fluoridating the water supply. At the start of the study in 2004, schoolchildren aged 7-8 in Calgary had fewer cavities than in Edmonton. Now, $65 \%$ of Calgary children - nearly two out of every three - have cavities and the number is rising. Meanwhile, compared with 14 years ago, the dental cavity rate for Edmonton children is virtually the same.

In the UK, where the government has announced it is planning to resume control of water fluoridation schemes, ${ }^{2}$ the findings are a valuable predictor of potential oral health improvements in future generations of 0-7-year-olds. Public consultations are a mandatory precursor of any water fluoridation scheme and the British Fluoridation Society (BFS) believes that the findings from Canada, published in the latest Community Dentistry and Oral Epidemiology, will explain powerfully and graphically the benefits of water fluoridation to the health of children.

The research team additionally looked for evidence of fluorosis, which causes a change in the appearance of tooth enamel. While they found that children in fluoridated areas had signs of fluorosis, as would be expected, in $99 \%$ of cases, it was mild. Additionally, in questionnaires which formed part of the study, parents' reports of the general health of their child's mouth were very similar in Calgary and Edmonton, with around half of parents in both cities rating their child's mouth health as excellent or very good. The benefits of water fluoridation at the optimum level far outweigh any possible disadvantage, of which fluorosis is the most common and likely.

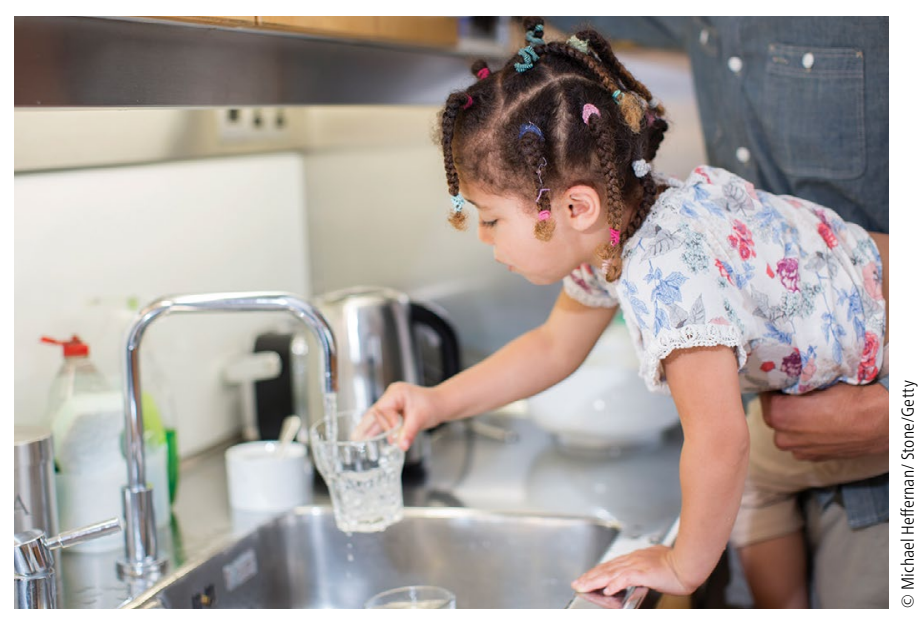

BFS Chair Dr Barry Cockcroft said: 'We welcome the findings of this carefully calibrated study by McLaren et al. which helps build on the existing body of research. By compiling the many authoritative studies from around the world, such as this latest work from Canada, we see a reassuring picture of the positive impact of water fluoridation on improving children's oral health and reducing inequalities.

'Let us not forget that water fluoridation positively benefits all ages and with the number of people living into older age, the ability to strengthen tooth enamel and reduce cavities with the simple addition of fluoride to water is a powerful and cost-effective tool, along with other preventive measures, of course'.

\section{References}

1. McLaren L, Patterson S K, Faris P et al. Fluoridation cessation and children's dental caries: A 7-year follow-up evaluation of Grade 2 schoolchildren in Calgary and Edmonton, Canada. Community Dent Oral Epidemiol 2021; doi: 10.1111/cdoe.12685.

2. Department of Health \& Social Care. Policy paper - Health and Care Bill: water fluoridation. 19 July 2021. Available at: https://www.gov.uk/government/publications/ health-and-care-bill-factsheets/health-and-care-bill-water-fluoridation (accessed August 2021). 